\title{
Determination of Vibrio parahaemolyticus from Retail Shrimp of South Gujarat of Navsari District and their Drug Resistance Pattern
}

\author{
R.K. Patel ${ }^{1}$, C.V. Savalia ${ }^{1}$, R. Kumar ${ }^{1 *}$, A.P. Suthar ${ }^{1}$, S.A. Patel ${ }^{1}$, \\ N.G. Patel ${ }^{2}$, I.H. Kalyani ${ }^{3}$ and S. Gupta ${ }^{2}$ \\ ${ }^{1}$ Department of Veterinary Public Health and Epidemiology, ${ }^{2}$ Department of Livestock \\ Products Technology, ${ }^{3}$ Department of Veterinary Microbiology, College of Veterinary science \\ \& Animal Husbandry, Navsari Agricultural University, Navsari-396 450, Gujarat, India \\ *Corresponding author
}

\section{A B S T R A C T}

In this study systematic bacteriological examination of aseptically collected 150 shrimp samples, 27 samples of hand swabs from fish handlers were collected from retail fish outlets, and 23 stool samples from patients suffered with digestive disturbances after consumption of seafood reported to private clinics, all from Navsari city were investigated.

\section{Keywords}

Shrimp, Vibrio parahaemolyticus, Antibiotic resistance

\section{Article Info}

Accepted:

24 January 2018

Available Online:

10 February 2018

\section{Introduction}

Aquaculture remains a growing, vibrant and important production sector for high-protein animal food that is easily digestible and of high biological value. Globally, marine and
The samples were enriched in Alkaline Peptone Water followed by direct plating on selective media viz. Thiosulfate Citrate Bile Salt Sucrose agar and Vibrio parahaemolyticus sucrose agar. All samples were brought to the laboratory for isolation, identification and characterization of $V$. parahaemolyticus isolates on the basis of their morphological, cultural and biochemical characteristics. Out of total 150 samples of shrimp $5(3.33 \%)$ isolates of $V$. parahaemolyticus were obtained which included $3(4.28 \%$, $3 / 70)$ from marine shrimp and $2(2.5 \%, 2 / 80)$ from freshwater shrimp samples. Out of 27 samples of the hand swabs of fish handlers, $2(7.40 \%)$ were positive for $V$. parahaemolyticus. However, none of 23 human stool samples was positive for the pathogen. All the $7 \mathrm{~V}$. parahaemolyticus isolates were further processed to study drug resistance pattern against 7 commonly used antibiotics by agar disc diffusion method. The $V$. parahaemolyticus isolates showed cent percent sensitivity towards Ciprofloxacin and Gentamicin, followed in descending order by Amikacin (85.71\%), Trimethoprim (85.71\%), Streptomycin (71.42\%) and Tetracycline (28.58\%). An intermediate sensitivity of isolates was noticed against Streptomycin (28.58\%) and Amikacin (14.29\%). All V. parahaemolyticus isolates were totally resistant to Penicillin. However, varying degree of resistance was observed against Tetracycline (71.42\%) and Trimethoprim (14.29\%). 
Biradar, 2002). Shrimp cultivation is an economically important agricultural activity worldwide. In international trade, the most prominent product from aquaculture is marine shrimp, with approximately 26 per cent of the total product comes from pond-reared Penaeid species i.e. Litopenaeus vannamei and Penaeus monodon (Shanmugasundaram et al., 2015). With its vast brackish water resources and congenial climatic conditions, India has good scope for shrimp production (Ponnusamyand Pillai, 2014).

Gujarat is having a vast brackish water area of 3.76 lakh hectares throughout $1,600 \mathrm{~km}$ long coastline which is ideal for shrimp culture. Large number of shrimp farms has been constructed and major activities related to shrimp culture have been concentrated on coastal belt of South Gujarat (Vadher and Kapila, 2014).

Shrimp cultivation faced serious problems with diseases caused by viruses and bacteria causing severe economic losses. Of the bacterial infections, Vibrio spp. is well recognized cause of mortality. $V$. parahaemolyticus, V. harveyi, V. anguillarum and $V$. vulnificus have been frequently associated with mortalities both in hatcheries and grow out ponds, too (Shanmugasundaram et al., 2015).

Shrimps and Prawns of various kinds have certainly been a source of protein for human consumptions from very early times. The most common Vibrio species found in farming phases of black tiger shrimp in India were $V$. alginolyticus, $V$. parahaemolyticus and $V$. vulnificus (Bhaskar and Setty, 1994).

The occurrence of $V$. parahaemolyticus in marine and estuarine environments is of special interest from the public health point of view too, since most outbreaks of gastroenteritis caused may result in more severe infections than those caused by sewage-borne viral and bacterial pathogens (Rippey, 1994). Vibrio parahaemolyticus has a worldwide distribution in estuarine and coastal environments and has been isolated from many species of fish, shellfish and crustaceans (FDA, 1992).

Vibrio parahaemolyticus is a Gram-negative, halophilic, non-spore forming rod, either straight or has a single, rigid curve. When grown in liquid medium, motility is exhibited by a single polar flagellum.

V. parahaemolyticus is inhibiting temperate and tropical estuarine, marine and costal environment worldwide (Baumann and Schubert, 1984).

The bacterium was first identified as a causative agent of human disease after an outbreak of gastroenteritis in Japan in 1950 (Joseph et al., 1982; Mahmud et al., 2006).

This human pathogen occurs naturally in the marine environments and frequently isolated from a variety of sea foods including codfish, sardine, mackerel, flounder, clam, octopus, shrimp, crab, lobster, crawfish, scallop and oyster (Su and Liu, 2007; Liston, 1990).

Consumption of raw or undercooked seafood, particularly shellfish, contaminated with $V$. parahaemolyticus lead to development of acute gastroenteritis characterized by diarrhoea, headache, vomiting, nausea, abdominal cramps and low fever. It is recognized as the leading cause of human gastroenteritis associated with seafood consumption in the world (Kaysner and DePaola, 2001; Su and Liu, 2007).

Clinical isolates of $V$. parahaemolyticus most often produce either the thermostable direct hemolysin $(T D H)$ or $T D H$-related hemolysin $(T R H)$ encoded by $t d h$ and trh genes, 
respectively. However, only bacteria producing virulence factors, i.e., TDH and/or $T R H$, are considered to be pathogenic and can cause acute gastroenteritis or invasive septicaemia (Bisha et al., 2012). Keeping in view the above points in the present investigation an attempt was made to study incidence of Vibrio parahaemolyticus along with enteropathogenic potential.

\section{Materials and Method}

\section{Samples}

A total aseptically collected 150 shrimp samples, 27 samples of hand swabs from fish handlers were collected from retail fish outlets, and 23 stool samples from patients suffered with digestive disturbances after consumption of seafood reported to private clinics, all from Navsari city were investigated.

\section{Shrimp samples}

Altogether 150 shrimp samples from different ecosystems viz. marine and freshwater comprising of shrimp and prawns like white leg shrimp, black tiger shrimp and brown shrimp (Metapenaeus dobsoni) sold in and around Navsari city were collected aseptically in sterile polythene bags. Each sample bag was labelled indicating code number, type of the sample, date of collection etc. Samples were placed in the insulated box containing ice and brought to the departmental P.G. laboratory for further investigation.

\section{The human samples}

From the human subjects, stool samples and hand swabs collected aseptically directly in APW enrichment broth and brought to the departmental laboratory and incubated at 35$37^{\circ} \mathrm{C}$ for $16-18 \mathrm{hrs}$.
Isolation and identification of $V$. parahemolyticus

Samples of freshwater and marine shrimps and prawns were subjected to obtain surface tissues, gills, and guts and hepato-pancreas. About 25g of each type of sample (Gills, Guts and Hepato-pancreas) was thoroughly triturated in a sterile mortar and pestle with use of $225 \mathrm{ml}$ PBS $(0.85 \% \mathrm{NaCl}), \mathrm{pH} 7.2-7.5$, than inoculate 3-tube, multiple dilution, alkaline peptone water (APW) MPN series (i.e., add $1 \mathrm{ml}$ portions of each 1:10 and higher dilution to sets of 3 tubes containing $10 \mathrm{ml}$ APW). Incubate tubes $16-18 \mathrm{~h}$ at $35-37^{\circ} \mathrm{C}$. Inoculations of MPN tubes completed within 15-20 min of dilution preparation. From the human subjects, stool samples and hand swabs collected aseptically directly in APW enrichment broth and brought to the departmental laboratory and incubated at 35$37^{\circ} \mathrm{C}$ for $16-18 \mathrm{hrs}$. Subsequently they were processed in similar procedures follow for shrimp samples. A loopful of culture from APW after 18-24h enrichment was streaked onto Thiosulfate citrate bile salt sucrose agar (TCBS) and Vibrio parahaemolyticus sucrose agar (VPSA) incubated at $37{ }^{\circ} \mathrm{C}$ for $24 \mathrm{~h}$. The characteristic large colonies $(3-4 \mathrm{~mm})$ with light blue or green centres on TCBS and VPSA were regarded as presumptive $V$. parahaemolyticus and further subjected to morphological, cultural and biochemical characterization. A series of biochemical tests as per BAM, USFDA method (Kaysner and DePaola, 2004) was used for the identification of Vibrio isolates.

\section{Antibiogram}

In this study, the antibiotic susceptibility tests were performed as per method described by Bauer et al., (1966) to find out the antibiotic resistance pattern of all Vibrio isolates. In vitro antibiotic sensitivity test of the isolates was conducted by paper disc diffusion method 
using the discs supplied by HiMedia Laboratories Pvt. Ltd., Mumbai. Isolates were subjected to antimicrobial sensitivity tests against 7 antibiotics viz., Amikacin, Ciprofloxacin, Gentamicin, Penicillin, Streptomycin, Tetracycline and Trimethoprim.

Vibrio isolates were grown in Tryptone soya broth (TSB) (HiMedia) for 12-18 hours. The grown cultures were swabbed on MullerHinton agar plates (MHA with $2 \% \mathrm{NaCl}$ final concentration) (HiMedia Laboratories Pvt. Ltd., Mumbai) with sterile cotton swabs and left for 30 minutes for pre-diffusion time. Then using an ethanol dipped and flamed forceps different antibiotic discs were placed on the agar surface at about two $\mathrm{cm}$ apart. The discs were slightly pressed with the forceps to make complete contact with the medium. The plates were incubated at $37^{\circ} \mathrm{C}$ for $18-24$ hours. After the incubation period, the diameter of inhibition zones were measured and compared with interpretative chart provided by the manufacturer and zones were graded as sensitive, intermediate and resistant.

\section{Results and Discussion}

Systematic bacteriological examination of total 150 shrimp and prawn samples resulted in the recovery of $5(3.33 \%) \quad V$. parahemolyticus isolates as shown in Table 1. The findings of the present study were in approximation to 5.5 per cent as reported by Khamesipour (2014). However, lower incidence of 0.5 and 1.8 per cent was recorded by Hosseini et al., (2004) and Raissy et al., (2015), respectively. In contrast to the findings of present work, earlier studies conducted by Kshirsagar et al., (2013); Sperling et al., (2015) and Shanmugasundaram et al., (2015) reported higher incidence of $11.66,80.80$ and 83.40 per cent, respectively.

Table.1 Isolation of $V$. parahaemolyticus from shrimp and human samples

\begin{tabular}{|c|c|c|c|c|c|c|}
\hline $\mathrm{Sr}$ & \multicolumn{2}{|r|}{ Type of the Sample } & \multirow{2}{*}{$\begin{array}{c}\begin{array}{c}\text { No. of } \\
\text { samples } \\
\text { examined }\end{array} \\
80\end{array}$} & \multirow{2}{*}{$\begin{array}{c}\begin{array}{c}\text { No. of } \\
\text { samples } \\
\text { positive }\end{array} \\
2\end{array}$} & \multicolumn{2}{|c|}{ Per cent value } \\
\hline \multirow[t]{2}{*}{1} & Shrimp & Fresh water shrimp/prawn & & & 2.50 & \multirow[b]{2}{*}{3.33} \\
\hline & Sample & Marine water shrimp/prawn & 70 & 3 & 4.28 & \\
\hline \multirow[t]{2}{*}{2} & Human & Hand swab from fish handlers & 27 & 2 & 7.40 & \multirow[b]{2}{*}{4.00} \\
\hline & Samples & Human stool sample & 23 & 0 & 0.00 & \\
\hline
\end{tabular}

Table.2 Antibiogram of $V$. parahaemolyticus $(\mathrm{n}=7)$ isolated from shrimp sample and human subjects

\begin{tabular}{|c|c|c|c|c|}
\hline $\begin{array}{c}\text { Sr. } \\
\text { No. }\end{array}$ & $\begin{array}{c}\text { Name of Antibiotic with } \\
\text { concentration in }(\boldsymbol{\mu g})\end{array}$ & Sensitive & Intermediate & Resistant \\
\hline 1. & AK (30) & $85.71 *(6 / 7)$ & $14.29(1 / 7)$ & $0(0 / 7)$ \\
\hline 2. & CIP (5) & $100(7 / 7)$ & $0(0 / 7)$ & $0(0 / 7)$ \\
\hline 3. & GEN (10) & $100(7 / 7)$ & $0(0 / 7)$ & $0(0 / 7)$ \\
\hline 4. & P (10) & $0(0 / 7)$ & $0(0 / 7)$ & $100(7 / 7)$ \\
\hline 5. & S (10) & $28.58(5 / 7)$ & $28.58(2 / 7)$ & $0(0 / 7)$ \\
\hline 6. & TE (30) & $0(0 / 7)$ & $71.42(5 / 7)$ \\
\hline 7. & TR (5) & $85.71(6 / 7)$ & $0(0 / 7)$ & $14.28(1 / 7)$ \\
\hline
\end{tabular}

Note: * Figures in the table indicate Per cent values and Amikacin (AK), Ciprofloxacin (CIP) Gentamicin (GEN) Penicillin (P) Streptomycin (S) Tetracyline (TE) and Trimethoprim (TR) 
This could be due to variation in the sample size, different geographical conditions etc.

In the present study, $V$. parahaemolyticus was found 7.4 per cent $(2 / 27)$ samples of the hand swabs of fish handlers as shown in Table 2. This finding is lower than that of Mohammed (2012) who reported 13.2 per cent (7/53) incidence in the hand swabs of fish handlers.

In the present study, none of 23 stool samples from patients suffered with digestive disturbances after consumption of seafood found positive for $V$. parahaemolyticus. Hernández-Díaz et al., (2015), VelazquezRoman et al., (2012) and Mohammed (2012) reported 2.4 per cent, 5.09 per cent and 7.7 per cent incidence of $V$. parahaemolyticus in human stool samples, respectively.

\section{Antibiogram}

The pattern of resistance of $V$. parahaemolyticus analyzed in this study is shown in Table 2. In the present study $V$. parahaemolyticus isolates were found variably resistant to the antibiotics tested.

All the $7 \mathrm{~V}$. parahaemolyticus isolates (5 from shrimp and 2 from human sample) were processed to study antibiotic resistance and sensitivity pattern against 7 commonly used antibiotics by agar disc diffusion method. The $V$. parahaemolyticus isolates showed cent percent sensitivity towards Ciprofloxacin and Gentamicin, followed in descending order by Amikacin (85.71\%), Trimethoprim (85.71\%), Streptomycin $(71.42 \%)$ and Tetracycline $(28.58 \%)$. An intermediate sensitivity of isolates was noticed against Streptomycin (28.58\%) and Amikacin (14.29\%). All V. parahaemolyticus isolates were totally resistant to Penicillin. However, varying degree of resistance was observed against Tetracycline (71.42\%) and Trimethoprim (14.29\%).
The occurrence of antibiotic resistant $V$. parahaemolyticus might be associated with indiscriminate or uncontrolled use of antibiotics to contain fish or shrimp diseases, faecal and industrial pollution of water bodies (Watkins and Cabelli, 1985).

\section{References}

Ayyappan, S. and Biradar, R. S. (2002). Fisheries education in India. Fishing Chimes, 22: 45-50.

Bauer, A. W., Kirby, W. M., Sherris, J. C. and Turck, M. (1966). Antibiotic susceptibility testing by a standardized single disc method. Am. J. of Clin. Patho., 45(4): 4593-4596.

Baumann, P. and Schubert, R. H. W. (1984). Family II. Vibrionaceae. In: Krieg, N.R., Holt, J. G. (Eds.), Bergey's Manual of Systematic Bacteriology. Williams and Wilkins Co., Baltimore, pp. 516-550.

Bhaskar, N. and Setty, T. M. R. (1994). Incidence of Vibrios of public health significance in the farming phase of tiger shrimp (Penaeus monodon). J. Sci. Food Agric., 66(2): 225-231.

Bisha, B., Simonson, J. and Janes, M. (2012). A review of the current status of cultural and rapid detection of Vibrio parahaemolyticus. Int. J. Food Sci. Technol., 47: 885-899.

Chatterjee, S., and Haldar, S. (2012). Vibrio related diseases in aquaculture and development of rapid and accurate identification methods. Journal of Marine Science Research and Development $S, 1$.

Food and Drug Administration (FDA) (1992). Bacteriological Analytical Manual 7th ed., USA 111-140.

Hernández-Díaz, L. D. J., León-Sicairos, N., Velazquez-Roman, J., FloresVillaseñor, H., Guadron-Llanos, M., Martinez-Garcia, J. J., Vidal, J. E and 
Canizalez-Roman, A. (2015). A pandemic Vibrio parahaemolyticus O3:K6 clone causing most associated diarrhea cases in the Pacific North west coast of Mexico. Front. Microbiol. 6: article 221 .

Hosseini, H., Cheraghali, A. M., Yalfani, R., and Razavilar, V. (2004). Incidence of Vibrio spp. in shrimp caught off the south coast of Iran. Food control, 15(3): 187-190.

Joseph, S. W., Colwell, R. R. and Kaper, J. B. (1982). Vibrio parahaemolyticus and related halophilic Vibrios. Crit. Rev. Microbiol., 10: 77-124.

Kaysner, C. A. and A. DePaola, Jr. (2004). Vibrio cholerae, V. parahaemolyticus, V. vulnificus and other Vibrio spp. In FDA Bacteriological Analytical Manual, 8th ed. revised, AOAC International, Gaithersburg, MD 9:9.019.27

Kaysner, C. A. and DePaola, A. (2001). Vibrio. In: Downes, F.P., Ito, K. (Eds.), Compendium of Methods for the Microbiological Examination of Foods, fourth ed. American Public Health Association, Washington, DC, pp. 405420.

Khamesipour, F., Noshadi, E., Moradi, M. and Raissy, M. (2014). Detection of Vibrio spp. in shrimp from aquaculture sites in Iran using polymerase chain reaction (PCR). AALC Bioflux, 7: 1-7.

Kshirsagar, D. P., Brahmbhatt, M. N., Chatur Y. A., and Singha, N. (2013). Studies on occurrence and distribution of virulent strains of Vibrio parahaemolyticus in finfishes and prawns from different ecosystem of Gujarat (India). J. Vet. Pub. Hlth., 11: 7-10.

Liston, J. (1990). Microbial hazards of seafood consumption. Food Technol., 44: 56-62.

Mahmud, Z. H., Kassu, A., Mohammad, A.,
Yamato, M., Bhuiyan, N. A., Nair, G. B. and Ota, F. (2006). Isolation and molecular characterization of toxigenic Vibrio parahaemolyticus from the Kii Channel, Japan. Microbiological Research, 161: 25-37.

Mohammed, E. A. M. (2012). The Role of Fish and Other Invertebrate Aquatic Organisms in Transmitting Some Bacterial Diseases to Man. (M. V. Sc. thesis pdf).

Ponnusamy, K., and Pillai, S. M. (2014). Evaluation of factors contributing to adoption of management practices productivity and net income in shrimp farming in Gujarat, India. Indian $J$. Fish, 61: 80-84.

Raissy, M., Rahimi, E., Azargun, R., Moumeni, M., Rashedi, M. and Sohrabi, H. R. (2015). Molecular Detection of Vibrio spp. in Fish and Shrimp from the Persian Gulf Journal of Food Biosciences and Technology, 5: 49-52.

Rippey, S. R. (1994). Infectious diseases associated with molluscan shellfish consumption. Clin. Microbio. Rev., 7: 419-425.

Shanmugasundaram, S., Mayavu, P., Manikandarajan, T., Suriya, M., Eswar, A., Anbarasu, R. (2015). Isolation and identification of Vibrio spp. in the Hepatopancreas of cultured white pacific shrimp (Litopenaeus vannamei). International Letters of Natural Sciences, 46: 52-59.

Sperling, L., Alter, T. and Huehn, S. (2015). Prevalence and Antimicrobial Resistance of Vibrio spp. in Retail and Farm Shrimps in Ecuador. J. Food Prot., 78: 2089-2092.

Su, Y. C., and Liu, C. (2007). Vibrio parahaemolyticus: a concern of seafood safety. Food microbiology, 24(6): 549558.

Vadher, K. H. and Kapila, M. (2014). Study on socio-economic profile of shrimp 
farmers of Gujarat State, India. International Journal of Fisheries and Aquatic Studies, 2: 202-205.

Velazquez-Roman, J., León-Sicairos, N., Flores-Villaseñor, H., VillafañaRauda, S., Canizalez-Roman, A. (2012). Association of pandemic Vibrio parahaemolyticus $\mathrm{O} 3: \mathrm{K} 6$ present in the coastal environment of Northwest
Mexico with cases of recurrent diarrhea between 2004 and 2010. Appl. Environ. Microbiol., 78: 1794-1803.

Watkins, K.D. and Cabelli, V.J. (1985). Effect of faecal pollution on $V$. parahaemolyticus densities in an estuarine environment. Appl. Environ. Microbiol., 49:1306-1313.

\section{How to cite this article:}

Patel, R.K., C.V. Savalia, R. Kumar, A.P. Suthar, S.A. Patel, N.G. Patel, I.H. Kalyani and Gupta, S. 2018. Determination of Vibrio parahaemolyticus from Retail Shrimp of South Gujarat of Navsari District and Their Drug Resistance Pattern. Int.J.Curr.Microbiol.App.Sci. 7(02): 2704-2710. doi: https://doi.org/10.20546/ijcmas.2018.702.328 